\title{
O TERRORISMO COMO RESULTADO DE RELAÇÕES DE PODER
}

\author{
Celso Eduardo Faria Coracini \\ Mestrando pela Faculdade de Direito da \\ Universidade deSão Paulo. \\ Advogado em São Paulo.
}

\begin{abstract}
Resumo:
Não é possivel a incriminação do terrorismo pela carga de subjetivismo que comporta, tanto sob a perspectiva da motivação do agente, quanto sob o foco da percepção psicológica da vítima, observadas as conseqüências disso para a legalidade penal. Assim, a utilização da expressão, notadamente após o episódio de 11 de setembro de 2001, em Nova York, é eminentemente retórica, velando a promoção de estratégias de poder como forma de produzir discursos de verdade no plano internacional.
\end{abstract}

Abstract:

The incrimination of terrorism is not possible, because of its subjective content, as much in the perspective of the agent's motivation as under the focus of the victim's psychological perception. Its consequences towards criminal legality shall be watched. Therefore, the use of this expression, mainly after the facts held on September, the $11^{\text {th }}$ in New York, is merely rhetorical, concealing the promotion of strategies of power, in order to produce discourses of truth, in international level.

Unitermos: terrorismo; Direito Penal Internacional; Direito Penal de consciência interior; relações de poder.

"(...) poder-se-ia chegar a supor inclusive que as coisas boas têm um valor pela forma insidiosa em que estão emaranhadas e talvez até cheguem a ser idênticas em essências às coisas más que parecem suas contrárias. Talvez!..."'

(Nietzsche, Além do bem e do mal)

1. Introdução.

O terrorismo assume, uma vez mais, posição central nas discussões atinentes ao Direito Penal Internacional. Talvez sinal do caráter francamente reativo

1. Todas as citações não-colhidas de textos $\mathrm{cm}$ portuguĉs foram traduzidas pclo autor, a partir das versōes indicadas nas referĉncias bibliográficas. 
do Direito Penal, ${ }^{2}$ e mesmo em razão da impossibilidade prática de permanecer ao abrigo dos ventos tempestuosos da vida política, é certo que a ineficácia do Direito Penal, também no plano internacional, abre espaço para os abusos de direito e para os atos de força. Em pouco tempo, acontecimentos de algum modo localizados difundemse a coletividades inteiras, neste mundo em contínua transformação, pela renovação do fenômeno de globalização, ${ }^{3}$ com o virtual encurtamento das distâncias, a velocidade da informação, sob os auspícios dos meios de comunicação e da tecnologia e, sobretudo, em razão da crescente identificação que os individuos ocidentais mantêm entre si, destacadamente no plano cultural. Ondas de terror se propagam...

Sobre que repousam? Sobre os atos de terrorismo propriamente ditos? Sobre o imaginário das coletividades, tornadas vulneráveis no calor dos fatos recentes, de gritante proporção, com os quais se identificam? Ou quiçá sobre os media,${ }^{4}$ que inflam a importância dos acontecimentos, sinalizam os pontos de vista institucionais, desnaturam o alcance dos fatos e das personagens?

A dificuldade de exprimir de maneira precisa e minimamente consensual os atos de terrorismo, tanto em documentos internacionais quanto no quadro das ordens jurídicas internas, deve algo à variedade de formas que podem eles assumir. Os acontecimentos que tiveram lugar em Nova York, no dia 11 de setembro de 2002, tornaram-se objeto de divulgação em massa. Após visitarem, pela mediação de um visor televisivo, as cenas dos crimes de seqüestro de aeronaves, de diversos homicídios aleatórios, seguidos da destruição de um símbolo do poder econômico dos EUA (as torres do World Trade Center), assim como do ataque a um símbolo do poder militar norte-americano (o Pentágono), os tão incrédulos como incontáveis olhos do povo ocidental, de um golpe, passaram a experimentar um especial sentimento de vulnerabilidade.

Noam Chomsky busca estabelecer, sob esse argumento, uma ligação com o fato de que o mundo dito 'desenvolvido' (a Europa e os EUA) jamais enfrentou ameaças externas de igual alcance, no âmbito do próprio território nacional. Ao contrário, a política externa americana, durante todo o século $\mathrm{XX}$, esmerou-se no

2. Scgundo Michel Massć, "o direito penal internacional sempre evoluiu sob a pressão dos acontecimentos (as duas guerras mundiais, o terrorismo, a internacionalização dos tráficos...) " ("La place du droit pénal dans les rélations internationales", Revue de sciences criminelles et de droit pénal comparé, Paris, n.1, jan/mar, 2000, p. 124). Contudo, cssc ramo do Dircito somente veio a excrcer um papel central na vida política intcrnacional a partir dos anos 1990.

3. O descnvolvimento da globalização revela tanto a 'compressão' do mundo, de um lado, como uma intensificação da consciência do mundo como um todo, de outro (ROBERTSON, Roland. Globalization - Social theory and global culture. London: Sage Publications, 1992, p.1I). Robertson indica, também, que o tema da modernidade se desenvolveu durante os anos 60 , a partir da mudança dos paradigmas de 'comunidade' (Gemeinschafit) $\mathrm{cm}$ direção ao de 'socicdadc' (Gesellschaft).

4. Sobre o poder dos meios de comunicação $\mathrm{c} o$ fato de que cles criam o ambiente necessário para o cspetáculo da jurisdição penal, cf. Sćrgio Salomào Shecaira. "Mídia c Crime", in SHECAIRA, Sćrgio Salomão (org.). Estudos Criminais em homenagem a Evandro Lins e Silva (Criminalista do Século). São Paulo: Mćtodo, 2001, pp.353-367. 
proveito dos conflitos no estrangeiro, e mesmo no impor-se pela força das armas, sem economia de vidas, por exemplo, no México, nas Filipinas, no Havai, ${ }^{5}$ e isto para não se alongar sobre suas intervenções 'estratégicas' na América do Sul (Chile, Argentina, Brasil, Colômbia). Talvez mesmo em razão disso, parte considerável do mundo considere os Estados Unidos como um país que lidera o terrorismo, em escala mundial. ${ }^{6}$

Para além dessas polêmicas pontuais, convém questionar-se sobre a capacidade moral de um Estado para eleger, de maneira isolada, os inimigos do mundo, pela escolha - guiada por interesses nem sempre explicitados - dos alvos de um ódio quase religioso, a mascarar um desejo singular de limpeza moral. O tema do "terror" e suas expressões adjacentes - "terrorismo" "terroristas" - recebe, sem dúvida, um tratamento retórico. Apenas à guisa de exemplo, a opinião pública mundial encontra dificuldades para distinguir quem, de fato, assumiu o papel de terrorista nos conflitos entre a Palestina e o Estado de Israel. ${ }^{7}$ Isso obriga a uma reflexão sobre o lugar da verdade e sobre os padrões (standard) que ela busca estabelecer, nas relações internacionais.

O conceito de "verdade" relaciona-se, estreitamente, com a conformação de sistemas de poder, responsáveis pela sua produção, manutenção e pelos efeitos de poder que ela desencadeia e que a reproduzem..$^{8}$ Bauman retoma essa idéia, em outras palavras, quando analisa o julgamento de Eichmann em Jerusalém e o argumento de seu defensor, Dr. Servatius, que sustentou, grosso modo, que Eichmann havia cometido atos em razão dos quais um vencedor é condecorado e um vencido enviado ao cadafalso: o poder - e, evidentemente, o poder instalado - declara o que é correto. ${ }^{9}$ O crime é, observadas essas premissas, uma construção.

Ninguém põe em dúvida que apareça o sistema penal como manifestação complexa do poder social, ainda que existam várias teorias para justificar essa idéia. ${ }^{10}$ No entanto, a reflexão sobre o terrorismo internacional deve tomar em conta certas circunstâncias globais, atuantes no nível social, político e histórico.

Ora, o discurso jurídico deve contentar-se com a verossimilhança, em

5. Noam Chomsky. Il de setembro (trad. de Luiz Antonio Aguiar). 3a cd. Rio de Janciro: Bertrand Brasil, 2002, pp. II-18; 25-30.

6. Illem, p. 25 .

7. Clıris Hedges. "The new Palcstinians revolt", Foreign Affairs, New York v. 80, n. 1, jan./fcb., 200।, pp. 124-138. Nesse cxcmplo, atua também a atcrradora banalização da violĉncia, quc ć, possivelmente, mais nefasta c desumana que o terrorismo unilateral.

8. Michel Foucault. Microfisica do Poder (trad.: Robcrto Machado). I la ed. Rio de Janciro: Graal, 1991 , p. 14.

9. Zygmunt Bauman. Modernidade e Holocansto (trad. Marcus Penchel). Rio de Janciro: Jorge Zahar Ed., 1998, p. 38.

10. Eugenio Raúl Zaffaroni. En busca de las penas perdidas: deslegitimación y dogmática jurílicopenal. Bogotá: Tcmis, p. 7. 
função de que lhe é inerente a busca constante pela reunião das condições de legitimidade, necessárias para a preservação de sua supremacia sobre outras formas de discurso não-hegemônicas, bem como para a manutenção de um determinado status de poder, que é a fonte dos discursos preponderantes. Deve-se isso à impossibilidade prática de atingir-se uma verdade satisfatória para o conjunto das culturas mundiais. Releva não se esquecer que os ideais democráticos não se contentariam jamais com a homogeneização das culturas e dos saberes, na criação de um consenso baseado na massificação, e não sobre os valores de pluralismo e tolerância, tão caros a uma Humanidade consciente de sua condição.

O debate sobre o terrorismo, tanto em plano nacional quanto internacional, suscita sempre uma aproximação que, longe de ser jurídica, ainda menos o é jurídico-penal. As dificuldades inerentes a sua definição jurídica são sintomáticas da insuficiência, e mesmo da inabilidade, do Direito Penal moderno no tratamento de uma realidade que the escapa.

Busca-se, pois, como principal objetivo, mostrar como o discurso sobre os atos de terrorismo prescinde de uma intervenção penal, por não haver espaço para a incriminação de puros subjetivișmos no Direito Penal e, de mesmo, em razão de que a legalidade de um crime nesses moldes esbarraria em exigências - políticas - de legitimidade.

2. Ordem mundial e os atos de terrorismo.

As definições de terrorismo, sem exceção, e mesmo sendo inevitavelmente tautológicas, referem-se às mais variadas condutas, no que concerne aos meios de execução ou aos resultados obtidos, aptos a provocar terror. Ora, a palavra "terror" é um sentimento de "medo extremo que transtorna, paralisa"". Se o resultado mais evidente do "terrorismo" é um 'sentimento', que o prende a julgamentos fundados "sobre uma apreciação subjetiva (e não sobre um raciocínio lógico)" 12 , ele depende de ressonâncias externas, muito mais que da motivação interior, de penível apreensão. A existência do terrorismo supõe seu receio e repúdio.

Seria importante, primeiramente, analisar o fenômeno do "terrorismo" a partir de três pontos de vista que se entrelaçam: a. o terrorismo como resultado de efeitos de poder, que não se remete a qualquer conceito absoluto e apriorístico de verdade, mas a uma expressão de vontade política hegemônica; b. nesse sentido, o terrorismo possui também uma face retórica, proveniente do poder estabelecido, com o escopo de alcançar a persuasão; c. e, finalmente, o terrorismo como determinante de uma cultura de dissensão, a partir do efeito multiplicador e vicioso que a violência e as respostas não-legitimadas proporcionam.

11. Paul Robcrt. Le Petit Robert. Paris: Socićtć du Nouvcau Littré, 1979, p. 1.949.

12. Idem, p. I.799. 
a) O terrorismo como expressão de vontade política.

A denominação "terrorismo", ou "atos de terrorismo" foi utilizada pela primeira vez por Gunzburg, na $3^{a}$ Conferência pela Unificação do Direito Penal, ocorrida em Bruxelas, no ano de 1930.'3

A expressão é, de maneira geral, associada à delinqüência política, no que concerne às motivações de seu agente. Segundo González Lapeyre, motivações políticas ou sociais podem encontrar-se na origem do delito terrorista, mas ele apenas adquire essa qualidade notadamente porque, além daquelas, persegue ele o objetivo de provocar uma situação alarmante, com o auxílio dos meios hábeis. ${ }^{14}$

Pérez Montero ${ }^{15}$ menciona três tipos de crimes terroristas. Um terrorismo de Direito Comum, que guia suas ações em vista de lucro, sendo o terror o meio para alcançar seus objetivos, sobretudo no campo da criminalidade, dos tráficos (de drogas, armas e pessoas) e da corrupção endêmica.

De outra parte, poder-se-ia identificar o terrorismo político-social, que persegue o triunfo de um ideal ou de uma concepção política ou social, tais como a liberação de um povo que se considere oprimido, ou sua independência. Neste caso, estar-se-ia diante de uma visão meramente utilitarista, em que os fins justificariam os meios violentos. ${ }^{16}$

Finalmente, desde a Revolução Francesa, adquiriu o terrorismo uma dimensão de Estado. Seguramente, o terrorismo de Estado apresenta características que o aproximam da guerra, declarada ou-não. No plano interior, pode exprimir-se como uma perseguição de minorias, ou de opositores do governo instituído, à frente do Estado (como exemplo, tem-se o "grande terror" jacobino, e também as execuções que tiveram lugar em Cuba, logo após a revolução que derrubou o regime ditatorial precedente, a perseguição aos curdos no Iraque, Irã e Turquia). Ora, esse gênero de terrorismo define-se por aqueles que resistem ao governo instituído, e que consideram abusivas as práticas do poder hegemônico. Não raro, o Estado, para além das trincheiras, considera os 'resistentes' como terroristas (do gênero 'político-social').

No plano externo, o terrorismo de Estado articula-se como demonstração de poderio militar e político (mencionem-se a respeito a Guerra dos Sete Dias de Israel,

13. Heleno Cláudio Fragoso. Terrorismo e Criminalidade Politica. Rio de Janciro: Forcnsc, 1981, p. 41; Edison Gonzalcs Lapcyrc. Aspectos juridicos del terrorismo. Montevidco: Amalio M. Fcrnandez, 1972, p. 9;

\section{Op. cit., p. 13.}

15. José Pćrez Montcro. "La lucha y la cooperación internacionales contra el terrorismo", Anuario Argentino de Derecho Internacional, Córdoba, v. 4, 1990-1991, pp. 94-100.

16 Nào ć objeto do presente texto a discussão das tcorias sobre o terrorismo como categoria dos crimes politicos (o que implicaria $\mathrm{cm}$ tratamento processual privilegiado a esses crimes). Para tanto, cf. Heleno Cláudio Fragoso. Op. cit., pp. 28-37; Josć Pćrcz Montcro. Op. cit., pp. 94-100; Luiz Régis Prado ct Erika Mendes de Carvalho. "Delito politico c terrorismo: uma aproximaçào conceitual", Revista dos Tribunais, São Paulo, v. 89, n. 771, jan. 2000, pp. 421-447. 
que marcou sua posição diante do mundo árabe, com apoio norte-americano; ou as recentes disputas entre Israel e a Autoridade Palestina, cujos territórios estão ocupados pelas forças israelitas, em gritante desproporção com respeito aos combatentes palestinos; ou, ainda, o massacre de judeus, comunistas e ciganos promovido pelos governos nazista e fascista da Alemanha e Itália, durante a Segunda Grande Guerra). Ora, a inserção desses comportamentos, levados adiante por Estados soberanos, como condutas criminais autônomas é duvidosa, ou, ao menos, suscita obstáculos de ordem, uma vez mais, política. Além disso, a discussão, nesses termos, coloca em causa a utilidade do Direito Penal Internacional, quando se trata de confrontos entre Estados ou entre Estados e grupos não-institucionalizados.

Ora, a configuração da política internacional favorece o multilateralismo nos dias de hoje, o que significa, apesar do poder determinante de algumas potências mundiais, que a política de alianças, ou, em outros termos, a cooperação entre os Estados, tomando em conta, sobretudo, o equilíbrio regionalizado, é tanto mais necessária que a instabilidade política tornou-se regra, em razão da crescente interdependência, em todos os domínios, mas sobretudo no plano econômico, entre os países.

Mister não se esquecer de que as violências ilegítimas no plano internacional se devem referir a um recurso jurídico, do mesmo modo que as teorias da pena nas ordens jurídicas nacionais. Consideradas essas violências como "rupturas" do Direito, desencadeiam elas a reação da pena criminal que, ao lado de outras funções, "evita o direito do mais forte e a justiça pelas próprias mãos das vítimas, que constituiriam outras rupturas do direito, conformando, em suma, um processo regulado para a solução de graves conflitos sociais" 17

Por outra parte, a resistência ao emprego do termo "terrorismo", por ocasião mesmo das Assembléias Internacionais, é compreensível, devido à dificuldade que impõe a sua definição. ${ }^{18} \mathrm{Na}$ realidade, as condutas que caracterizariam atos de terrorismo, previstas nas convenções internacionais, resoluções das Nações Unidas e ordens jurídicas nacionais consultadas, ${ }^{19}$ em nada diferem das semelhantes condutas

17. Günther Stratenwerth. Acción y resultado en derecho penal. Buenos Aires: Ed. Hammurabi, 1991, pp. 80-81.

18. A Convenção de Washington de 1971, da Organização dos Estados Americanos (OEA), chegou a provocar dissidências, mas findou por incluir csse termo no titulo da Convençĩo (Convençìo para prevenir e sancionar os atos de terrorismo contra as pessoas e a extorsüo conexa quando eles mostram ama transcendência internacionar", c, ainda, no texto de seu artigo 1 (Edison Gonzales Lapeyrc. Op. citt., pp. 31-33).

19. Cf., sobre as regras internacionais, G. Gilbert. "The 'law' and 'transnational terrorism", Netherlands Yearbook of International Law, Haguc, v. 26, 1995, pp. 3-32; Luigi Migliorino. "La dichiarazione delle nazioni unite sulic misure per climinarc il terrorismo internazionale", Rivista di Diritto Internazionale, Milano, v.78, n. 4, 1995, pp. 962-972; Robert Kolb. "Universal criminal jurisdiction in matters of international terrorism: some reflections on the status and trends in contemporary international Jaw", Revue Hellenique de Droit International, Paris, v. 50, n. I, 1997, pp. 43-88; Josć Perez Montero. "La lucha y la cooperación internacionales contra el terrorismo", Anuario Argentino de Derecho Internacional, Córdoba, v. 4, 1990-1991, pp. 91-169; en Italic: Adolfo Cerctti. "O tcrrorismo de esquerda na Itália nos anos setenta-causas c remédios" (trad.: Ana Paula Zomer), Revista Brasileira de Ciências 
previstas pelo Direito Penal comum. A diferença parece residir não apenas na motivação de causar "terror" mas, também, no efeito de "terror" provocado.

De acordo com Fragoso, que se apóia em documentos internacionais, inexiste figura específica denominada "terrorismo", seguindo a designação empregada no caso de diferentes crimes caracterizados por consideráveis danos a bens ou pessoas, pela criação real ou potencial de "terror" ou intimidação generalizada e, ainda, pela finalidade político-social, por meio de violência contra pessoas e bens. $O$ "terror" e a intimidação constituem-se em razão do emprego de meios que provocam perigo comum, e mesmo do caráter aleatório das vítimas dos atentados individuais. ${ }^{20}$

Ora, o problema inicial persiste. Se o elemento constitutivo do terrorismo é a intimidação com vistas a alcançar um objetivo previamente determinado, a impossibilidade de prever, mantendo-se a obediência à legalidade criminal, ${ }^{21}$ quais atos seriam especialmente dignos de merecer a reprovação jurídico-penal parece certa. Mas a insistência em situar o 'combate' ao 'terrorismo internacional' como prioridade das politicas internacionais pode conduzir a um questionamento do recurso retórico aos discursos de 'terror', como simples maneira de impor estratégias de poder.

b) O terrorismo como recurso retórico de poder.

No plano internacional, a politização do discurso jurídico é ainda mais evidente que nos planos nacionais. O emprego retórico da expressão "terroristas" responde a necessidades de apontar os inimigos dos valores mais cáros a um modelo social e político, sensivel a toda resistência.

Ora, esse argumento reduz-se ao percurso semântico assegurado pela legalidade e pela carência de legitimação. Sendo indiscutivel que o Direito Penal, de um ponto de vista sociológico, é. empregado como instrumento de controle social, ele produz, de mesmo, o efeito de evitar a autotulela, pelo monopólio estatal da violência.

Criminais, São Paulo, v. 5, n. 18, abr./jun., 1997, pp. 9-25; à Portugal: Mariana Sotto Maior. "Le terrorismc”, Documentação e Direito Comparado: Boletim do Ministério da Justiça, Lisboa, n. 57/58, 1994, pp. 269292; Otilia Veiga. "Mesures contre le terrorisme internacional", Doctumentação e Direito Comparado: Boletion do Ministério da Justiça, Lisboa, n. 39/40, 1989, pp. 363-377; cn Espagnc: Ignácio Berdugo Gomez de La Torre; J. Ramos S. "Reflexiones politico criminales sobre el terrorismo", Derecho Penal y Criminologia, Bogotá, v. 10, n. 34, cnc./abr., 1988, pp. 91-104. Pour unc ćtude comparćc, v. Heleno Cláudio Fragoso. Op. cit., pp. 56-88.

20. Heleno Cláudio Fragoso. Terrorismo e criminalidade politica. Rio de Janciro: Forense, 1981, p. 12.

21. Michel van de Kcrchove concentra ĉnfase sobre a dilatação da legalidade criminal, cm nivel das fontes, ocorrida com o desenvolvimento do Dircito Pcnal Internacional, c a recepção das fontes não cscritas, assim como sobre a crescentc imprecisão de diversos textos juridicos ("Éclatement ct récomposition du droit pćnal", Revue de sciences criminelle et de droit pénal comparé, Paris, n.1, jan/mar, 2000, pp. 89). Deve-se, contudo, rejeitar ao máximo este último aspecto do mencionado fenômeno, pois a ausĉncia de scgurança jurídica pode se constituir $\mathrm{cm}$ amcaça aos dircitos fundamentais do homem, quando a esfera penal entra cm jogo, tanto mais que o Dircito Penal não é o único, c certamente tampouco o mais cficaz método de prevençào c repressão de condutas socialmente prejudiciais. 
Entretanto, internacionalmente, as intervenções militares das Nações Unidas não encontraram, até o presente momento, artifícios para se desembaraçar dos interesses imediatos dos países constituintes, notadamente daqueles que participam do Conselho de Segurança. Parece ser essa uma das razões pelas quais o Direito Penal Internacional deve permanecer restrito a uma reduzida gama de incriminações, e submetido, ao menos durante um período de transição, ao principio da jurisdição universal, até a completa instalação do Tribunal Penal Internacional.

Segundo Zaffaroni, ${ }^{22}$ a legitimidade do sistema penal, como discurso jurídico específico (o "saber" penal) de controle social institucionalizado, é a característica que confere a esse sistema a sua racionalidade. Ora, reconhecendo-se a especificidade de um sistema de poder, possível que os óbices de legalidade não sejam insuperáveis. Considerando que o poder se conforma a partir de uma rede de relações entrecortadas e descontínuas, que se manifestam através das instituições e com o auxílio de sistemas de exclusão que filtram as palavras, as expressões das condutas, a hermenêutica fundamental das normas sociais, partilham-se, o verdadeiro e o falso, já no momento da constituição dos topo $i$ argumentativos. O que é presumido não se sujeita a discussão. Assim, a legitimidade sobre que se baseiam as denominações dos atos de terrorismo não escapam aos 'jogos de verdade', nem tampouco às constrições da vontade de poder - sempre segura e convencida de si-, que buscam uma hegemonia, ainda que transitória. ${ }^{23}$

As questões sobre o terrorismo suscitam, pois, o problema da extensão da ameaça representada pelos "inimigos" dos poderes, de algum modo, hegemônicos. Quando o objetivo dos atos de terror ultrapassa os interesses puramente individuais, vez que se reportam, em geral, a ideais coletivos e mesmo nacionais, a delimitação precisa e segura dos alvos de sua repressão se torna impossivel. Eis outro efeito perverso do emprego retórico da expressão, vez que "o terrorista jamais está só" ${ }^{24}$ Nesse sentido, "o objeto 'terrorismo' se constrói sobre um horizonte de responsabilidade coletiva" 25 Os destinos das coletividades (dir-se-ia, inocentes) ligam-se estreitamente aos destinos dos Estados, quando dotados de legitimidade social, tanto quanto aos atos de terror provocados em nome de seu futuro. Nas palavras de Salazar, "o terrorista se constitui em refém de seu ato, por ele incriminando a coletividade" 26

22. Op. citt, pp. 7-19.

23. Cf. Michel Foucault. L'ordre du discours. Paris: Gallimard, 1971, pp. 14-23. E ainda, do mesmo autor, $A$ verdade e as formas juridicas (trad. de Roberto Cabral de Mclo Machado c Eduardo Jardim Morais). Rio de Janciro: Nau Ed., 1996. Foucault identifica a cxistência de uma política de verdadc, cujo regime depende das relações constituídas de métodos e procedimentos de eleç̧ão de um saber que funda, explica c sustenta o poder, de mancira recíproca, mas nào-absoluta.

24. Philippc-Joscph Salazar. "Lc terroristc: construction rhćtorique d'un objet social", in Chazel, F. ct Commaille, J. (org.) Normes juridiques et régulation sociale. Paris: Librairic Génćrale de Droit ct Jurisprudence, 1991, p. 419.

25. Idem.

26. Philippc-Joscph Salazar. Op. cil., pp. 420. 
Sustentar o caráter retórico da expressão "terrorismo" não significa apoiar as práticas violentas. Mas talvez não difiram em tanto dos crimes ditos comuns. Por vezes, justificam-se elas pela sucessão de verdades, ou mesmo tornam-se legitimadas pela História. Os movimentos de liberação das colônias com relação a suas metrópoles transgrediam a ordem jurídica estabelecida, e por vezes de maneira violenta. Enquanto práticas ilegítimas e ilegais, encontravam-se previstas e sancionadas pelas ordens jurídicas da época. Mas de tempos em tempos, uma crise de legitimidade se abatia sobre aquele sistema. A descolonização tardia dos países africanos apresentou conseqüências brutais, em sua época (as sangrentas batalhas na Algéria constituem induvidosos exemplos, pois a França insistia em não a perder. Nessa época, a democracia e a liberdade talvez fossem valores retoricamente menos úteis...). Observando-se de perto, as conseqüências dos anos de colonização persistem brutais, mas pouco se cogita em procurar as causas da miséria e do paradoxal endividamento desses países, decerto porque essa situação não suscita sentimentos assemelháveis aos de "terror" no mundo ocidental.

Em uma concepção pragmática da verdade, "ela somente pode ser definida por referência aos critérios internos de uma dada teoria, sistema ou paradigma" ${ }^{27}$ Essa dimensão deve acompanhar as discussões acerca do terrorismo, pois a existência de diferentes perspectivas sobre os mesmos atos e contextos não pode ser, jamais, deixada de parte. A tolerância e o pluralismo devem permanecer como os valores fundamentais do Direito Internacional, e guiar os debates no campo penal.

c) O terrorismo como determinante de uma cultura de dissensão.

O terrorismo define-se também em função da perda de controle de uma situação. De outro modo não se produziriam os efeitos de 'terror' Sendo verdadeiro que os responsáveis pelo terrorismo representam coletividades (ou, ao menos, seus desejos), não se poderia negar o fenômeno coletivo que o 'terror' propriamente dito desencadeia. Resulta ele da impossibilidade, ou mesmo da falta de conhecimento, sobre as vias de reação. Assim, finda compreensível (mas não-justificável) que as respostas ao 'terrorismo', como supra concebido, beirem a irracionalidade, ou mesmo a supere.

Levanta-se, por conseguinte, o problema do simbolismo que se forma ao redor das práticas terroristas, no momento em que se confundem as ações e as reações, provocando um terrorismo recíproco, com forte apelo psicológico. "Em outras palavras, o terrorismo enquanto objeto do social instala a repetição no âmago do medo. Com isso, ele cumpre uma função, falando-se corretamente, religiosa. Por ele funciona um controle da aparência e do desaparecimento que, na perspectiva mesmo da politica, revela isto: o medo do outro é justa, o ódio de outrem é bom,o distanciamento, moral. Quando o discurso judiciário criminaliza o discurso terrorista,

27. Boaventura de Souza Santos. Introdução a uma ciência pós-moderna. Rio de Janciro: Graal, 1989, p. 73. 
longe de acalmar neste a carga fetichista do atentado, ele ativa toda a sua energia simbólica" 28

Nesse sentido, torna-se possivel a percepção da relatividade dos julgamentos sobre as práticas violentas, por definição inegociáveis. É sobretudo preciso sublinhar que não se pode controlar um sentimento como o 'terror' e, menos ainda, apreendê-lo em uma definição jurídica. Não poderia o resultado abster-se de ser vago e ambíguo. Por vezes, lembrando os "jogos de verdade" já mencionados, visa-se, com isso, favorecer a adesão a uma tese (ou a uma versão do conflito) e, em outras ocasiões, a definição ambígua pretende criar a impressão (verossimilhança, ou aparência de verdade) de ser ela, precisamente, o sentido buscado por todos. ${ }^{29} \mathrm{~A}$ ambigüidade atua, também ela, nos dois terrenos, ainda que opostos.

A violência é uma representação que transborda do plano meramente jurídico (onde se entrevê a violência simbólica). "A violência coloca-se no lado da transcendência, o terror no lado dos efeitos mundanos. À primeira, a anomia, à segunda, a anomalia, ai encontra-se a recusa da responsabilidade" ${ }^{30}$ Reconhecer ao terrorismo esse conteúdo social desintegrador, que se estende ao discurso - e ações - de seu, assim chamado, 'combate', poderia levar a uma reflexão mais ampla e produtiva, além da simples busca de sua definição jurídica.

Desse modo, as respostas ao terrorismo, que escapem ao caminho institucionalmente legítimo (o que se encontra ainda em construção, no plano internacional), podem significar a independência estrutural da força (vis) com relação ao Direito (tanto mais que não acompanha as necessidades mutáveis dos fatos, ou ao menos não possui os instrumentes de contenção exigidos), como fundamento derradeiro do poder. ${ }^{31} \mathrm{O}$ único resultado social possível é a formação e desenvolvimento de uma cultura de dissensão, a qual, longe de conduzir à paz (presumidamente objetivo das políticas de prevenção e repressão do terrorismo, por mais tênue que seja, também, o conceito de paz), afasta e distancia os sujeitos participantes (da comunidade), ao redor do 'terror'

3. Breves notas sobre a experiência brasileira no campo do terrorismo.

O período histórico em que o Brasil conheceu práticas terroristas sistemáticas corresponde àquele em que vigeu uma ditadura militar, entre 1964 e 1984. Os governos autoritários, que cassaram direitos políticos de maneira arbitrária, impuseram restrições à liberdade de expressão, e mergulharam os direitos humanos na

28. Boaventura de Souza Santos. Introdlução a uma ciência pós-moderna. Rio de Janciro: Graal, 1989, p. 73.

29. Tercio Sampaio Ferraz Jr. Introdução ao estudo do direito: técnica, decisào, dominação. 2 a ed. São Paulo: Atlas, 1994, p. 344.

30. Philippe-Joscph Salazar. Op. cit., p. 419

31. Tercio Sampaio Ferraz Jr. Op. cit., 346. 
sombra dos calabouços, encontram-se na origem da criminalidade política violenta da época. $^{32}$

Essa criminalidade compreendeu principalmente o seqüestro de aeronaves e de diplomatas em troca da liberação de prisioneiros políticos (destinados ao exílio) ou somas de dinheiro, também obtidas em roubos a bancos, para financiar as atividades de resistência (tendo ocasionado algumas mortes), e ainda outras atividades consideradas subversivas, tais como a panfletagem ou manifestações públicas de desacordo com o poder estabelecido. ${ }^{33}$ As táticas de guerrilha também foram empregadas por alguns setores dos movimentos de oposição, que se colocavam na clandestinidade.

Mesmo nessa ocasião, não houve definição legal de terrorismo, mas descrições de condutas contrárias ao regime militar (notadamente em crimes contra $o$ Estado), no quadro de uma ideologia de segurança nacional.

Os primeiros textos legais nesse sentido remontam ao início do século, com o Decreto n. 4.269, de 17.01.1921 (que reagia à propagação do anarquismo), e a Lei n. 38, de 04.04.1935 (que fazia referência aos crimes "contra a ordem política e social"), editada sob o governo autoritário encabeçado por Getúlio Vargas, a qual foi substituída pela Lei n. 1.802, de 05.01 .1953 , por ocasião da redemocratização. Apenas no dia 13:03.1967, o Decreto-Lei n. 314 foi editado, mencionando, pela primeira vez os "crimes contra a segurança nacional", considerada como valor fundamental da Nação. Após, com a Lei de Segurança Nacional, n. 6.620, de 17.12.1978, reforçoul-se a inexistência de uma ação delituosa específica denominada "terrorismo". Todas as condutas descritas possuem, simplesmente, uma finalidade política, ou de desestabilização de ordem político-social. ${ }^{34}$

Importa lembrar que, após o final da ditadura militar, alguns "terroristas" da época surgiram na cena política. Há vários deputados, e mesmo um antigo ministro da Justiça, que tomaram parte das guerrilhas, na época da última ditadura militar, sendo que um deles participou do seqüestro de um diplomata norte-americano (Charles Burke Elbrick, aos 04.09.1969). Isso é representativo das análises empreendidas até este ponto. As perspectivas, o poder e os destinatários dos atos 'ameaçadores' emprestam contornos à expressão 'terroristas'. Estes não existem a priori, e o 'terror' não se pode limitar por definições estritas de condutas dignas de repercussão penal (pois, sendo o caso, a discussão não teria razão de ser).

4. A proscrição histórica do Direito Penal de consciência.

As tentativas de incriminação do terrorismo pecam pela previsão de uma miríade de comportamentos que conduzem a resultados já incriminados na maior parte

32. Heleno Cláudio Fragoso. Op. cit., 108.

33. Heleno Cláudio Fragoso, Op. cit., pp. 108-114.

34. Helcno Cláudio Fragoso, Op. cit., pp. 89-103. 
das ordens jurídicas ${ }^{35}$ (e que recebem um tratamento diferenciado, quando transcendem as fronteiras das nações), seja como crimes de dano, seja como crimes de perigo comum. A única particularidade estaria na finalidade político-social, ou na motivação de provocar 'terror'

Ora, "uma conduta que apenas atrai a atenção caso se conheça o universo interior do Autor não pode ser concebida legitimamente como um delito, vez que em outros casos o interior seria o único fundamento da pena" ${ }^{36}$ O Direito Penal moderno pune somente fatos, que resultam de condutas humanas, ainda que não se destaquem elas das intenções que as inspiram. Os pensamentos puros, de todo modo, devem permanecer afastados do Direito Penal.

Não se constitui em obrigação do Estado - e, menos ainda, mediante os instrumentos penais - zelar pela solidariedade ou a decência moral de seus cidadãos. Apenas os Estados autoritários (tais como a antiga União Soviética ou o Estado alemão nazista) tentaram criminalizar os pensamentos. "Em um Estado de liberdades não apenas as cogitationes são isentas de responsabilidade, mas também toda conduta que se realiza no universo privado e ainda toda conduta exterior que não seja per se pertinente" 37

Nesse sentido, quando são analisados os crimes de perigo; duas correntes são admitidas: o conceito objetivista, majoritário, pelo qual o perigo deve existir objetivamente, como realidade, a excluir os elementos subjetivos, tais como o temor ao perigo, compreendida a "consciência do perigo" por seu criador (base emocional do perigo). Deve, pois, o perigo ser concebido como real e não apenas como um ens imaginationis, ou, segundo Hälschner, um "filho de nossa ignorância" 38 De outra parte, "as teorias subjetivistas confundem, assim, o julgamento do perigo como sendo um puro erro intelectual" " ${ }^{39}$ Ora, a questão nodal concerne precisamente às múltiplas possibilidades de diferentes percepções (freqüentemente aleatórias por ocasião dos atentados terroristas) pelos indivíduos, da real dimensão do perigo, da ameaça que sobre eles paira.

Isso obriga a necessárias avaliações do estado evolutivo das sociedades contemporâneas. A reconhecida complexidade dessas sociedades deve-se - como argumento central - não a critérios econômicos ou culturais, mas a uma configuração de conhecimentos, eles mesmos constituídos de diversas formas de conhecimentos ajustados a várias práticas sociais. ${ }^{40}$

35. Luiz Rćgis Prado ct Erika Mcndes de Carvallıo. "Delito político c tcrrorismo: uma aproximaçào conccitual”, Revista dos Tribunais, São Paulo, v. 89, n. 771, jan. 2000, p. 446.

36. Jakobs, Günther. "Criminalización en cl estadio previo a la lésion de un bien juridico", cn Estudios de de Derecho Penal (trad. de Enrique Pcriaranda Ramos, Carlos J. Suárez González ct Manucl Cancio Mcliá) Madrid: Civitas; UAM, 1997, p. 302.

37. G. Jakobs. Op. cit., p. 303.

38. Rui Carlos Percira. O dolo de perigo. Lisboa: Lex, 1995, p. 20.

39. Idem.

40. Boaventura de Souza Santos. Introdução a unna ciência pós-moderna. Rio de Janciro: Graal, 1989, p. 47 
Em um periodo pré-finalista da teoria da ação, eram as "forças 'misteriosas e incalculáveis' que determinavam as 'condições de vida' e o próprio sentido da existência humana" "Al Assim, urgia explicar as condutas, antes de tudo, no mundo exterior, e, apenas em momento posterior, na mente humana. Como afirma Jakobs, "o conceito moderno de culpabilidade é filho do mundo desmistificado" ${ }^{42} \mathrm{o}$ que oferece amplas possibilidades de justificação da responsabilidade dos individuos por suas condutas, à condição de que sejam legítimas as normas jurídicas.

Ora, as estruturas normativas buscam estabelecer uma paz jurídica, que significaria a ausência de perturbação das próprias normas jurídicas. Não se confunde ela, apesar dos desejos dos moralistas, com a paz social, tão mencionada (e para a qual não parece ser, o Direito Penal, solução). A possibilidade de paz social encontra-se em um plano interno, e ela mensura-se apenas pela reunião dos sentimentos dos individuos que compõem as comunidades.

Quando se cuida de atos de terrorismo, as ordens jurídicas punem, freqüentemente, condutas em função de seus significados para as vítimas. O papel da vítima, in casu, é o de experimentar um sentimento de 'terror'. Claro está que "não se trata, nesses tipos penais, de crimes de preparação, mas unicamente do crime parcial de perturbação da paz juridica. O autor arroga-se, nos dias de hoje, tão simplesmente a configuração do substrato cognitivo da norma em vigor. Na medida em que a paz 'pública ou 'interior' ou adjetivada de outra maneira não seja sinônimo dessa paz jurídica, apenas pode-se constatar um ataque contra ela se, verificando a lesão de um inicio de ação, deprecia-se o domínio privado do autor e se o pune em razão de uma conduta que será exterior somente no futuro, ou seja, caso se o considere como inimigo" 43

Retoma-se, uma vez mais, o tema do inimigo. Sem negar a possibilidade de sua existência no plano político-social, que guarda as mais estreitas relações com a imposição de um poder que se propõe a convencer de sua legitimidade, a escolha de um inimigo - e sua perseguição - não pode ter lugar no campo penal, no seio de uma ordem jurídica que elege valores tais como a tolerância e o pluralismo, a partir de que não se concebe a intervenção penal em situações nas quais outros meios de controle social poderiam agir de maneira eficaz (princípio da subsidiariedade e da necessidade da intervenção penal).

Possível que a evolução da Humanidade não lhe tenha trazido vitórias sobre os preconceitos e as desconfianças com relação ao diferente, estrangeiro. Possivel mesmo que a seqüência de guerras e catástrofes não esteja terminada. As prioridades dos que pensam pertencer a este mundo parecem carentes de atualização. $O$ 'terrorismo'

41. Günther Jakobs, "El principio de culpabilidad", en Esludios de de Derecho Penal (trad. de Enrique Pcñaranda Ramos, Carlos J. Suárcz Gonzálcz ct Manucl Cancio Mcliá) Madrid: Civitas; UAM, 1997, p. 368.

42. Idem.

43. Günther Jakobs, op. cit., p. 318. 
é, também ele, uma praga que devasta os corações e espíritos humanos. Mas retornar tantos passos atrás, para ressuscitar a incriminação de idéias não-associadas a condutas, em momento anterior a sua exteriorização, não se justifica, considerado o atual estágio de desenvolvimento da doutrina penal. E os resultados - violentos, injustos, cruéis dessas condutas parecem ser já objeto de várias incriminações. Os necessários passos adiante compreendem, ao contrário, a disposição de resolver as graves questões concernentes à partilha de poder no mundo, além das dificuldades de conceber o respeito ao outro.

\section{Conclusões.}

Das reflexões apresentadas, é possivel desembocar em algumas conclusões, necessariamente parciais em razão da complexidade do objeto considerado:

I - deve-se considerar que o Direito Penal propriamente dito atua, no plano da eficácia social das normas jurídicas, apenas reativamente ${ }^{44}$

II - a complexidade do mundo moderno e a globalização assumem o papel de catalisadores dos acontecimentos 'terroristas';

III - o 'terrorismo' existe em função do sentimento que determinados atos de violência desencadeiam - o 'terror' - e em função da consciência da vulnerabilidade que ele compreende;

IV - o 'terror' insere-se nos moldes das práticas discursivas, o que explica o recurso a 'jogos de verdade' os quais objetivam provocar efeitos de poder, reflexo da vontade politica hegemônica;

V - o emprego da expressão 'terrorismo' é retórico, pois busca persuadir da existência de uma ameaça aleatória e irracional, portanto incontrolável, contra a verdade hegemônica;

VI - a busca das fontes das ameaças 'terroristas' suscita o problema da indicação de inimigos e, consequentemente, de obstáculos à tolerância;

VII - deve-se admitir que uma escalada da violência se produz quando as respostas a atos de 'terrorismo' escapam das vias do Direito, e mais especificamente do Direito Internacional Público, favorecendo uma cultura de dissensão;

VIII - não há no Brasil uma figura autônoma de 'terrorismo' Busca-se reprimir o crime organizado, assim como os 'crimes contra o Estado';

IX - a incriminação do 'terrorismo' propriamente dito encontra, ainda, óbice na proscrição do Direito Penal de consciência interior, pois compreende uma especial motivação para a ação delituosa;

$\mathrm{X}$ - o aspecto relacionado à ausência de controle sobre os sentimentos experimentados pelas vítimas também guarda caráter fortemente subjetivo, que implica a noção de terrorismo; -

44. As politicas sociais, $\mathrm{c}$ mesmo, $\mathrm{cm}$ alguns casos, as politicas de scgurança pública, não tomam partc do Dircito Pcnal propriamente dito. 
XI - o Direito Penal Internacional deve auxiliar a restringir o "terrorismo" pela persecução dos crimes transnacionais organizados, e não mediante um alargamento ilegítimo do princípio da legalidade.

As leis devem ser garantes da liberdade, e não instrumentos de agressão, lembra Gomes de La Torre. ${ }^{45} \mathrm{O}$ fato de que o Direito Penal não oferece a solução a todos os males não é novidade. A urgência em interromper o ciclo de violência existente, compreendida a violência estatal (a utilização indiscriminada da força, com a justificação de 'combate' à criminalidade), é um desafio posto pelos direitos humanos. ${ }^{46}$

Mas no que concerne ao Direito Penal Internacional, ainda que suas características se construam por progressivos esforços de sistematização, tendendo a ser estimulado pela implementação do Tribunal Penal Internacional, é-lhe absolutamente necessário banir a retroatividade e ainda evitar que o Direito Penal se revele de fonte puramente costumeira. ${ }^{47} \mathrm{O}$ valor de segurança jurídica também deve subsistir no que se refere às relações internacionais.

A recusa ao 'terrorismo' é necessária, mas seria preciso antes saber do que se trata. E, considerando estar-se defronte de um fenômeno politico, sua prevenção se deveria fazer pensar no campo político. No momento em que se realizam condutas já previstas criminalmente, como parte de estratégias políticas, caso provoquem elas resultados danosos tal como legalmente previstos, não se percebe razão para que o Direito comum (nacional ou internacional) deixe de exercer seu papel habitual. Ao contrário, optando-se pela tática do confronto, punindo-se independentemente do advento de resultados, assume-se o risco de catalisar a violência, inclusive estimulando a sensibilidade social ao sentimento de 'terror'

Se a utilização de expressões em torno do 'terror' é meramente retórica, "é claro que a criminalização do terror tende a colocar em circulação generalizada uma cultura da dissensão. O objeto terrorista não é sinal de constrangimento político, ele é sinal de que todo agregado social fundado na legitimidade da falta de trocas, sobre o abandono dos valores, está condenado a sofrer, em cheio, uma diversificação fatal e indiferenciadora do trágico". 48

Às vezes, uns e outros perdem o controle sobre os procedimentos de administração do 'terror'. Nesses momentos, ele se torna um simples detalhe em face da conservação do poder. E as condutas atentatórias aos bens jurídicos e às liberdades fundamentais perdem mesmo parte de sua gravidade diante de um monstro de aspecto variável, que emociona, mais que atemoriza. Então, torna-se o 'terror' uma desculpa

45. Ignacio Bcrdugo Gomes de La Torre. "La legislación penal antiterrorista", Derecho Penal y Criminologia, Bogotá, v.1I, n. 38, mayo/ago., 1989, pp. 24.

46. Antonio Luís Chaves de Camargo. "Direitos Humanos c Dircito Penal: limites da intervençào no Estado Democrático de Dircito", in SHECAIRA, Sérgio Salomão (org.). Estudos Criminais em homénagem a Evandro Lins e Silva (Criminalista do Século). São Paulo: Mćtodo, 2001, p. 80.

47. Michcl Massć. Op. cit., p. 130.

48. Plıilippe-Joseph Salazar. Op. cit., p. 42।. 
para que os efeitos de persuasão e de poder entrem em cena. Melhor que o Direito Penal se mantenha à distância, sem ilusões de inocência...

São Paulo, agosto de 2002.

Bibliografia.

BAUMAN, Zygmunt. Modernidade e Holocausto (trad.: Marcus Penchel). Rio de Janeiro: Jorge Zahar Ed., 1998.

CAMARGO, Antonio Luis Chaves de. "Direitos Humanos e Direito Penal: limites da intervenção no Estado Democrático de Direito", in SHECAIRA, Sérgio Salomão (org.). Estudos Criminais em homenagem a Evandro Lins e Silva (Criminalista do Século). São Paulo: Método, 2001, pp. 73-80.

CERETTI, Adolfo. "O terrorismo de esquerda na Itália nos anos setenta-causas e remédios" (trad.: Ana Paula Zomer), Revista Brasileira de Ciências Criminais, São Paulo, v. 5, n. 18, abr./jun., 1997, pp. 9-25.

FERRAZ JR., Tércio Sampaio. Introdução ao estudo do direito: técnica, decisão,

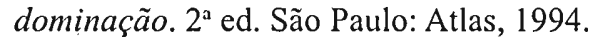

FOUCAULT, Michel. L'ordre du discours. Paris: Gallimard, 1971.

FOUCAULT, Michel. A Microfisica do Poder (trad. de Roberto Machado). $11^{\text {a }}$ ed. Rio de Janeiro: Graal, 1993.

FOUCAULT, Michel. $A$ verdade e as formas juridicas (trad. de Roberto Cabral de Melo Machado e Eduardo Jardim Morais). Rio de Janeiro: Nau Ed., 1996.

FRAGOSO, Heleno Cláudio. Terrorismo e criminalidade política. Rio de Janeiro: Forense, 1981.

GILBERT, G. “The 'law' and 'transnational terrorism'”, Netherlands Yearbook of International Law, Hague, v. 26, 1995, pp. 3-32.

GOMEZ DE LA TORRE, Ignacio Berdugo. "La legislación penal antiterrorista", Derecho Penal y Criminologia, Bogotá, v.11, n. 38, mayo/ago., 1989, pp. 23-37.

GOMEZ DE LA TORRE, Ignacio Berdugo; RAMOS S., J. "Reflexiones político criminales sobre el terrorismo" Derecho Penal y Criminologia, Bogotá, v. 10, n. 34, ene./abr., 1988, pp. 91-104.

JAKOBS, Günther. "Criminalización en el estadio previo a la lésion de un bien jurídico", en Estudios de de Derecho Penal (trad. de Enrique Peñaranda Ramos, Carlos J. Suárez González et Manuel Cancio Meliá) Madrid: Civitas; UAM, 1997, pp. 293324.

KERCHOVE, Michel van de. "Éclatement et récomposition du droit pénal", Revue de sciences criminelle et de droit pénal comparé, Paris, n.1, janv./mars, 2000, pp. 5-15. 
KOLB, Robert. "Universal criminal jurisdiction in matters of international terrorism: some reflections on the status and trends in contemporary international law". Revue Hellenique de Droit International, Paris, v. 50, n. 1, 1997, pp. 43-88.

HEDGES, Chris. "The new Palestinians revolt", Foreign Affairs, New York v. 80, n. 1, jan./feb., 2001, pp. 124-138.

MAIOR, Mariana Sotto. "Le terrorisme", Documentação e Direito Comparado: Boletim do Ministério da Justiça, Lisboa, n. 57/58, 1994, pp. 269-292.

MASSÉ, Michel. "La place du droit pénal dans les relations internationales" Revue de sciences criminelle et de droit pénal comparé, Paris, n.1, janv./mars, 2000, pp. 123-131.

MIGLIORINO, Luigi. "La dichiarazione delle nazioni unite sulle misure per eliminare il terrorismo internazionale”, Rivista di Diritto Internazionale, Milano, v.78, n. 4, 1995, pp. 962-972.

PEREIRA, Rui Carlos. O dolo de perigo. Lisboa: Lex, 1995.

PEREZ MONTERO, José. "La lucha y la cooperación internacionales contra el terrorismo", Anuario Argentino de Derecho Internacional, Córdoba, v. 4, 1990-1991, pp. 91-169.

PRADO, Luiz Régis; CARVALHO, Erika Mendes de. "Delito político e terrorismo: uma aproximação conceitual", Revista dos Tribunais, São Paulo, v. 89, n. 771, jan. 2000, pp. 421-447.

ROBERTSON, Roland. Globalization - Social theory and global culture. London: Sage Publications, 1992.

SALAZAR, Philippe-Joseph. "Le terroriste: construction rhétorique d'un objet social” in CHAZEL, F et COMMAILLE, J. (org.) Normes juridiques et régulation sociale. Paris: Librairie Générale de Droit et Jurisprudence, 1991, pp. 415-421.

SANTOS, Boaventura de Souza. Introdução a uma ciência pós-moderna. Rio de Janeiro: Graal, 1989.

SHECAIRA, Sérgio Salomão. "Mídia e Crime", in SHECAIRA, Sérgio Salomão (org.). Estudos Criminais em homenagem a Evandro Lins e Silva (Criminalista do Século). São Paulo: Método, 2001, pp.353-367.

STRATENWERTH, Günther. Acción y resultado en derecho penal. Buenos Aires: Ed. Hammurabi, 1991.

VEIGA, Otilia. "Mesures contre le terrorisme internacional", Documentação e Direito Comparado: Boletim do Ministério da Justiça, Lisboa, n. 39/40, 1989, pp. 363-377.

ZAFFARONI, Eugenio Raúl. En busca de las penas perdidas: deslegitimación y dogmática juridico-penal. 2ª ed.Bogotá: Temis, 1990. 